\title{
DAVID'S AUTHORSHIP OF THE SO-CALLED SIE-BOEN-LIAN OPERATION FOR ENTROPION, AND SUGGESTED IMPROVEMENTS*
}

BY

\author{
E. RAUBITSCHEK
}

Baghdad

IN February, 1931, an article describing an operation for entropion by Sie-Boen-Lian appeared in the Klinische Monatsblätter für Augenheilkunde. It so happened that Dr. J. David, who was not an ophthalmic specialist but a general practitioner, had several years before shown me a copy of an article of his own on this very subject. I therefore drew his attention to Sie-Boen-Lian's communication, with the result that he claimed his rights as the originator of the technique in question, and two months later, in April, 1931, the following correction was published:

The simple operative procedure for mass treatment of entropion . . by Sie-Boen-Lian (Djokjakarta, Dutch East Indies) shows such extensive conformity with the method described in 1923 in Arch. Ophtal., Paris, 40, 737, that the priority of the idea undoubtedly rests with the earlier author, Dr. J. David.

Meanwhile, I received a letter from Professor A. von. Szily, Editor of the Klin. Mbl. Augenheilk., thanking me for my part in discovering the plagiarism. But the error proved more tenacious than the truth, and the operation went by the name of the second "inventor ". Miric' (1938) and Kettesy (1948) cite Sie-Boen-Lian without any mention of David. It is my hope to defend the rights of the real author, now deceased, and to save his name from oblivion.

David's operation, as it should be called, combines effectiveness with good cosmetic appearance. It was my effort to ascertain its true author that first encouraged me to try it, and, leaving my own method which I had found satisfactory up to that time, I soon adopted David's operation and introduced certain variations which appear to be real improvements worth retaining.

\section{Method}

The following is a description of the form of David's operation which has proved to be the best. In accordance with David and

* Received for publication November 24, 1949. 
all the other authors cited, it is here assumed that an upper lid is to be operated on, but in opposition to them I claim that it is also applicable mutatis mutandis to the lower lid, with which I have had equally good results.

(1) The field of operation is disinfected, and the conjunctiva anaesthetized by instillation of procaine.

(2) Novocaine (4 per cent.) adrenaline solution is injected with the lid everted over Brana's or (ireenholm's everter. Without piercing the tarsus, the needle

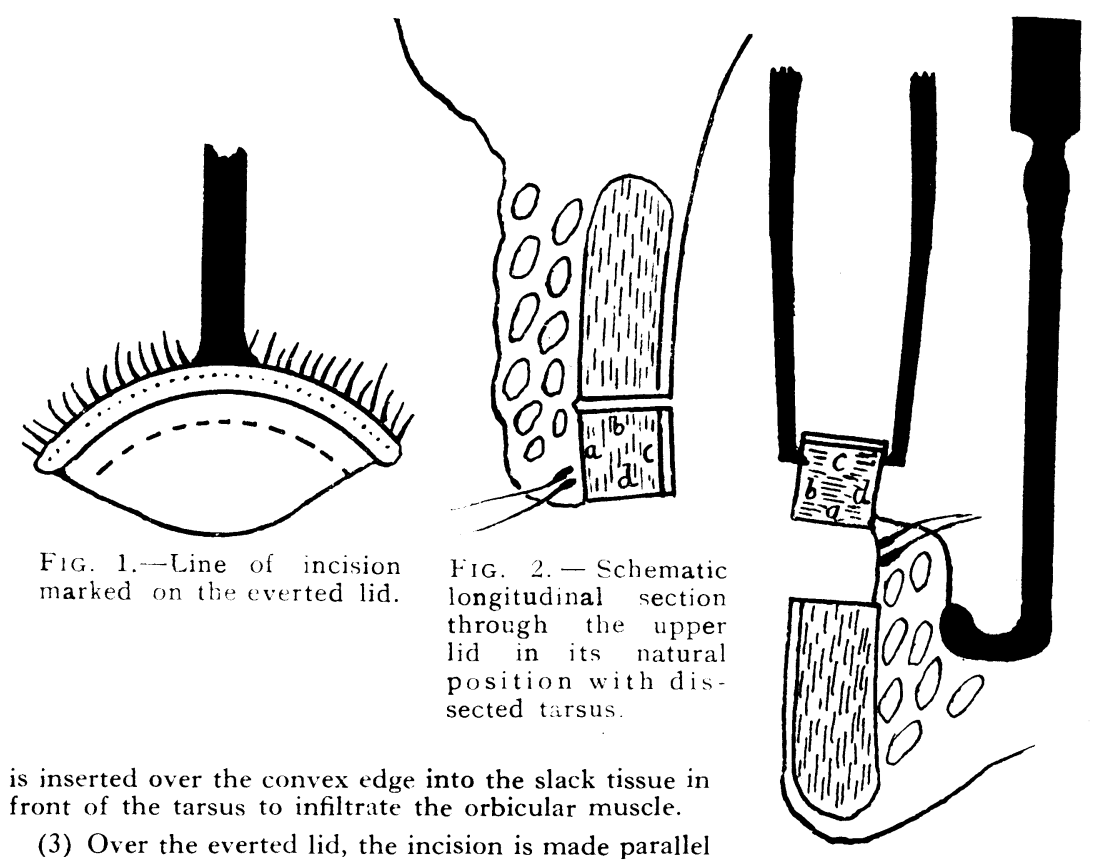

(3) Over the everted lid, the incision is made paralle to the margin, along its entire length and through the whole thickness of the tarsus. Thus a strip as wide as the intermarginal surface is separated from the remainder of the tarsus (Figs 1 and 2). Unless the entropion happens to be confined to the middle part of the lid, the everter is pushed into each corner of the lid and the incision is continued into each extremity of the tarsus. After returning the everier to the assistant, the surgeon seizes the distal strip of the tarsus with a forceps and, tilting that structure towards himself, stretches its connections with the orbicularis muscle and disconnects them by scratching with the point of the scalpel until the roots of the cilia

FIG. 3.- Schematic longitudinal section through the everted upper lid. The distal part of the tarsus is held by the forceps and pulled a way from the muscular layer after being cut right down to the roots of the lashes. The shading marks the vertical direction of the two parts of the tarsus. are seen (Fig. 3). In contrast with the freeing of the anterior surface of the distal part of the tarsus from its connections with the orbicularis muscle, no analogous procedure takes place for the anterior surface of the proximal part of the tarsus. This is my first deviation from the original method of David, and here I am in accordance with Mirić. This omission is desioned to avoid unnecessary injury. 
The separated distal part of the tarsus has an almost square cross-section. Since such designations as "anterior" and "posterior". "superior" and "inferior" become ambiguous when the lid is everted, I propose to use the following unequivocal expressions' (see Figs 2, 3, 4, 5, and 7).

" $a$ ", anterior surface freed from its connections with the muscular tissue

" $b$ ", sectional surface originally situated above

" $c$ ", posterior surface covered with conjunctiva

" $d$ ", intermarginal surface originally situated below,

(4) Three double-armed No. 1 sutures in two different colours, such as one black and two white, are used. The middle of the proximal part of the tarsus is seized with the forceps and stretched forward (Fig. 4). The two needles of the black suture: are introduced, about $4 \mathrm{~mm}$. apart, into the anterior surface of the tarsus through the soft muscular tissue in a vertical direction following the Meibomian ducts, and are made to emerge in the sectional area with the cross-sections of the ducts (Fig. 5). Similarly, both pairs of needles with white sutures are inserted, one into the nasal third and the other into the temporal third of the tarsus, so that all six ends of the sutures emerge at approximately equal distances (Fig. 6). Both ends of each suture are pulled out

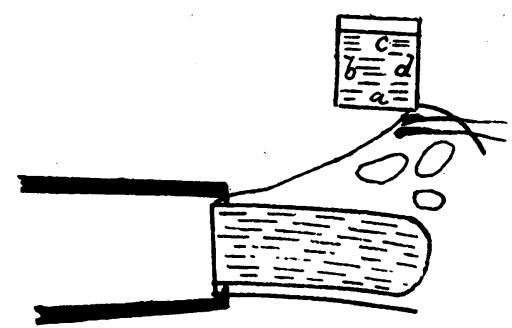

FIG. 4.-Proximal part of the tarsus seized by the forceps and pulled forwards.

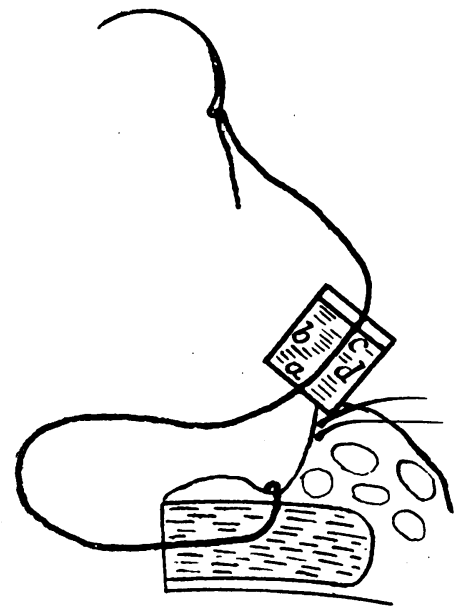

FIG.5.-Suture sewn through both parts of the tarsus, a schematic longitudinal section.

together, so that they project from the sectional area in equal lengths. Now the six needles are inserted one after the other at equal distances into the distal part of the tarsus, the first and the last being situated at either extremity of the section. The needles are inserted into surface " $a$ " and emerge from surface " $c$ " (Fig. 6). Finally, the two ends of each suture are pulled out together, the new lid-border being held in place by the closed forceps. Thus the contact of the surfaces is strengthened and any haemorrhage which may occur after relaxation of the pressure exercised by the everter is checked.

The introduction of the needles from the anterior surface of the tarsus is my second innovation, in contrast with the authors cited who insert them from behind. The advantage is that the three loops, being buried in the tissue, will not rub the cornea.

The effect of the suture is to turn the distal part of the tarsus forwards through $90^{\circ}$ (Fig. 7):

(i) $a$, originally the anterior surface, is turned upwards to join by healing with the sectional area of the proximal part;

(ii) $b$, the sectional surface, becomes the posterior suríace;

(iii) $c$, the posterior surface with conjunctiva, becomes the marginal surface;

(iv) $d$, the margin, is substituted for $a$ in the plane of the outer surface of the lid. 


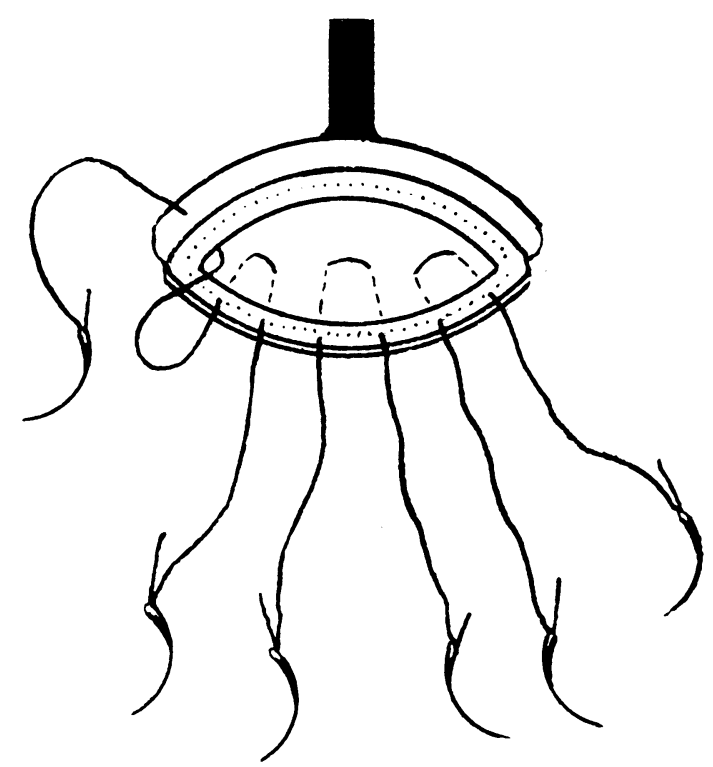

Fig. 6.--Position of sutures within the everted upper lid. The sectional surfaces of both parts of the tarsus are recognizable by the points marking the cross-sections of the Meibomian ducts. All the threads are embedled in the proximal part of the tarsus. The first needle on the right has alrealy pierced the distal part, entering surface a (original anterior surface, here invisible) and emerging from surface $c$ (original posterior surface covered with conjunctiva, here visible).

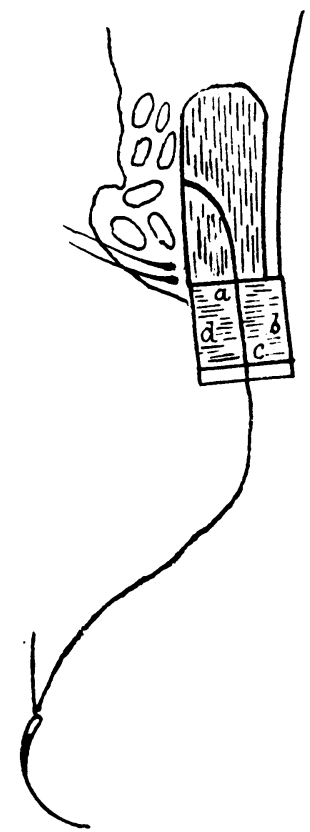

FIG. 7. - Final effect of sutures shown in a longitudinal section of the upper lid in its natural position (compare Fig. 2).

Thus the lashes, if previously directed downwards, are now directed forwards. The surfaces " $a$ ", " $b$ ", " $c$ ", and " $d$ " being almost equal in breadth, no deformation of the margin or of the lid will result. On the contrary, the previous boat-shaped crookedness of the eye-lid will be straightened.

According to David and Sie-Boen-Lian the sutures are now knotted; Miric uses small beads for this purpose, but Kettesy rejects them. My third modification is to avoid knotting the sutures at all. Their friction in the stitch canals provides sufficient security, and knotting is redundant. Tightly drawn sutures are apt to cause unevenness in the new lid-margin, ard post-operative swelling of the lid may cause the stitches to cut into the flesh, whereas with unknotted sutures the stitch canals simply slide along to conform with the swelling, and the set of the lid remains undisturbed. When the swelling subsides the distal part of the tarsus is again pushed back with the closed forceps to consolidate the effect of the suture. The unknotted sutures are shortened to equal lengths, about $5 \mathrm{~cm}$., and left hanging.

(5) My fourth modification is a new method of drissing. Over both lids of each eye (assuming that the two upper lids have been overated on) is laid a sterile patch of gauze, and the two patches are fixed by one 'ong, narrow, plaster strip, stretching from temple to temple over the bridge of thi nose. The lower halves of the patches are folded upwards so that only the upper lids remain covered, 
and each set of six ends of thread is turned up over its own patch. A closely twisted gauze roll (about 0.5 to $1 \mathrm{~cm}$. thick) is placed upon the patch on each upper lid just over the incision. A slight pressure on this gauze roll further everts the lid border through almost another $90^{\circ}$, thus increasing the effect of the suture to almost $180^{\circ}$. The lashes which have been pointing forwards are now made to turn upwards, against the outer skin of the lid. This pressure is exerted continuously by a bandage, which is stretched from the right temple over the bridge of the nose to the left temple and fixed thus:

First Turn: from the occiput, over the right auricle, to the right external canthus, over the left eyebrow, and back to the occiput;

Second Turn: over the right eyebrow to the left external canthus, over the left auricle, and back to the occiput;

Third Turn: over the right auricle across the bridge of the nose, over the left auricle, and back to the occiput (this last turn describes a slightly downward convex curve).

Each turn has the effect of lifting one half of one lid and fixing it in the everted position as by a sling. The first turn lifts the outer half of the right upper lid, the second turn the outer half of the left upper lid, and the third turn the inner halves of both upper lids. If only the right upper lid has been operated on, the second turn is omitted; vice versa, if only the left upper lid has been operated on, the first turn is omitted. The lashes, now directed upwards, are held in position by this bandage. The suture-ends must, of course, be relaxed after completion of the dressing, so that they do not exert any pressure on the lid border. To apply this dressing to the lower lids the bandage is passed under the auricles instead of over them.

The dressing covers the upper lids but allows the palpebral fissures to be opened so that the patient may see his way about. After five days the threads are removed by cutting one end of each pair and drawing out the other end. The bandage is then put on for one more day without the sutures. Immediately after the bandage is finally removed an ectropion of the lid margin appears, with the lashes directed upwards close to the skin, but the normal position is soon restored.

All the cited authors agree that the advantages of David's operation are its efficacy, permanence, and admirable cosmetic effect, since the skin remains intact, and no disfigurement can result from turning the distal strip, the dimensions of which are unchanged.

It is a further proof of the value of this operation that yet another independent but very similar description has recently been published by Torgersruud (1950).* This author, writing from Ethiopia, recognized the possibility that some similar method had already been published, and anticipated criticism by drawing attention to his lack of access to medical literature. I must claim a similar indulgence in respect of the probable incompleteness of my references. Torgersruud's method is in fact identical with David's, except in the use of double sutures. The effect which he obtains by the additional sutures is brought about in a bloodless manner by my fourth modification, my peculiar method of bandaging, described in step (5).

\footnotetext{
*EDITOR's Note. Though it appeared first in this Joumal, Dr. Torgersruud's article was not in fact received for publication until some time later than Dr. Raubitschek's.
} 


\section{Summary}

The real inventor of the so-called Sie-Boen-Lian operation for entropion was Dr. J. David. His operation is described and the following improvements are proposed by the present author:

(1) to avoid severing the connections of the proximal part of the tarsus with the orbicular muscle;

(2) to insert the threads from the anterior surface of the tarsus and bury the loops in the tissue

(3) to avoid knotting the threads;

(4) to bandage the eyes in such a way as to evert the lids still further during the healing process.

\section{REFERENCES}

DAvid, J. (1923). Arch. Ophtal., Paris, 40, 737.

KetTesy, A. (1948). British Journal of Ophthalmology, 32, 419.

Mikić, B. (1938). Klin. Mbl. Augenheilk., 101, 381.

RAUBitsChEK, E. (1922). Ibid., 68, 618.

'Sie-Boen-Lian (1931). Ibid., 86, 225: see also Editor's Correction (RICHTIGSTELLI'N(), Ibid., 86, 518.

TORGERSRUCD, T. (1950). British Journal of Ophthalmology, 34, 555. 